\title{
Microsymposium
}

MS81.006

\section{Direct methods for the 21st century}

V. Elser $^{1}$

${ }^{1}$ Cornell University, Department of Physics, Ithaca, USA

We describe a general method for obtaining structures from diffraction data that can be applied to non-crystalline and magnetic materials.
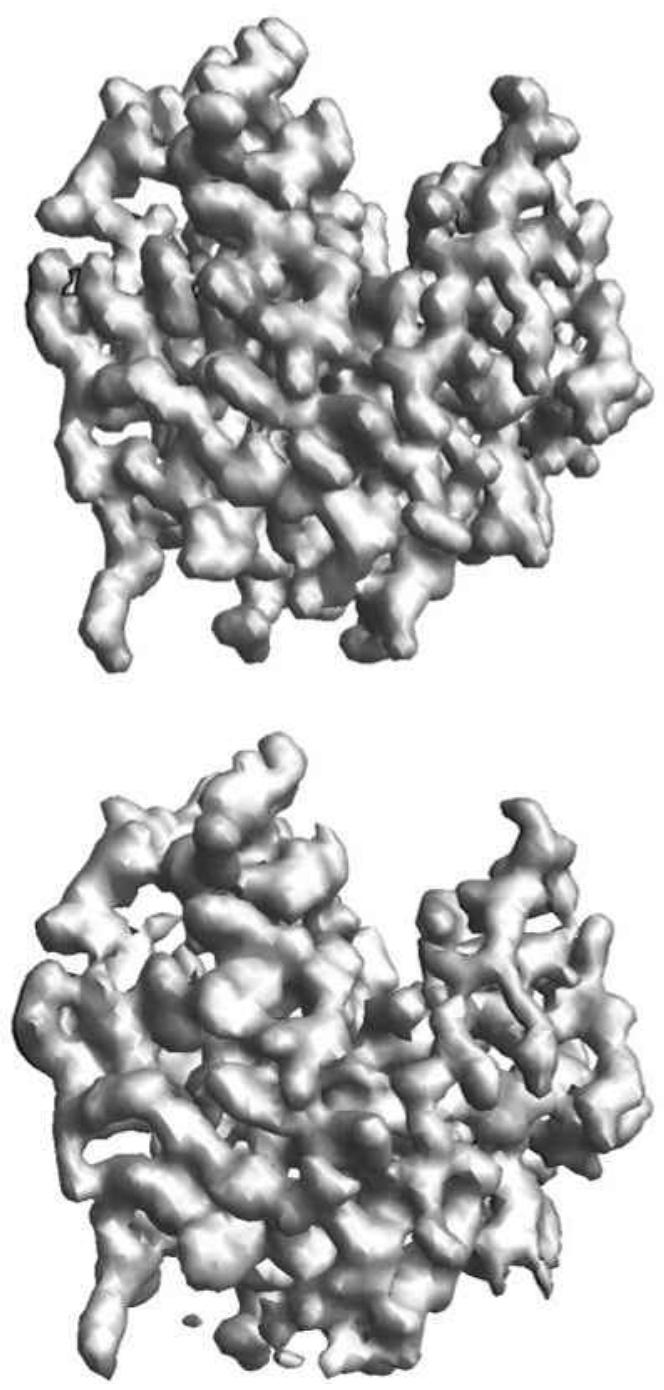

Keywords: direct methods, phase problem 